\title{
Treatment of Intrabony Defects With an Enamel Matrix Protein Derivative or Bioabsorbable Membrane: An 8-Year Follow-Up Split-Mouth Study
}

Anton Sculean, ${ }^{*}$ Frank Schwarz ${ }^{\dagger}$ Asta Miliauskaite, ${ }^{\ddagger}$ Alice Kiss, ${ }^{\ddagger}$ Nicole Arweiler, $§$ Jürgen Becker, ${ }^{\dagger}$ and Michel Brecx*

Background: Treatments with either an enamel matrix protein derivative (EMD) or guided tissue regeneration (GTR) have been shown to promote periodontal regeneration. However, until recently, only limited data have been available on the long-term clinical results following these regenerative techniques. Therefore, the aim of this study was to present the 8-year results of a prospective, controlled, split-mouth clinical study evaluating the treatment of intrabony defects with EMD or GTR.

Methods: Ten patients, each of whom displayed one pair of intrabony defects located contralaterally in the same jaw, were randomly treated with EMD or with GTR by means of bioabsorbable membranes. The following clinical parameters were evaluated at baseline and at 1 and 8 years after treatment: plaque index (PI), gingival index (GI), bleeding on probing (BOP), probing depth (PD), gingival recession (GR), and clinical attachment level (CAL). The primary outcome variable was CAL. No statistically significant differences between the groups were found at baseline.

Results: The sites treated with EMD demonstrated a mean CAL change from $9.5 \pm 1.2 \mathrm{~mm}$ to $6.3 \pm 1.3 \mathrm{~mm}(P<0.001)$ and $6.7 \pm 1.6 \mathrm{~mm}$ $(P<0.001)$ at 1 and 8 years, respectively. No statistically significant differences were found between the 1- and 8-year results. Sites treated with GTR showed a mean CAL change from $9.7 \pm 1.3 \mathrm{~mm}$ to $6.7 \pm 0.9 \mathrm{~mm}$ $(P<0.001)$ at 1 year and $6.8 \pm 1.2 \mathrm{~mm}(P<0.001)$ at 8 years. The CAL change between 1 and 8 years did not present statistically significant differences. Between the treatment groups, no statistically significant differences in any of the investigated parameters were observed at 1 and at 8 years. However, the study does not have the statistical power to rule out the possibility of a difference between the two groups.

Conclusions: Within their limits, the present results indicate the following: 1) the clinical improvements obtained following treatment with EMD or GTR can be maintained over a period of 8 years; and 2) further studies of much higher power need to be performed to support equivalence. J Periodontol 2006;77:1879-1886.

\section{KEY WORDS}

Clinical study; enamel matrix proteins; guided tissue regeneration; membranes.

\footnotetext{
* Department of Periodontology, Radboud University Medical Center, Nijmegen, The Netherlands. $\dagger$ Department of Oral Surgery, Heinrich Heine University, Düsseldorf, Germany.

‡ Department of Conservative Dentistry and Periodontology, University of Saarland, Homburg, Germany.

$\S$ Department of Operative Dentistry and Periodontology, Albrecht-Ludwigs University, Freiburg, Germany.
}

he goal of regenerative
periodontal therapy is
to fully restore the tooth's supporting apparatus that has been lost following inflammatory periodontal disease or injury. It is characterized by the formation of new cementum with inserting collagen fibers, new periodontal ligament, and new alveolar bone. $^{1}$

Several treatment modalities, such as the use of different types of bone grafts, root surface demineralization, guided tissue regeneration (GTR), growth factors, or the application of an enamel matrix protein derivative (EMD), have been employed with varying degrees of success to predictably accomplish this goal. ${ }^{2-7}$ Treatment with GTR involves the placement of a bioabsorbable or non-resorbable barrier membrane over the periodontal defects and denuded root surfaces, thus allowing periodontal ligament (PDL) and bone cells to selectively repopulate the isolated spaces. ${ }^{5}$ The rationale for the clinical use of EMD is the

doi: 10.1902/jop.2006.060002 
observation that enamel matrix proteins (EMPs) are deposited along the surface of developing tooth roots prior to cementum formation. ${ }^{7}$ It has been suggested that EMPs are involved in the formation of acellular extrinsic fiber cementum and may trigger the differentiation of progenitor cells into cementoblasts. ${ }^{7} \mathrm{EMD}$ may upregulate intracellular cyclic adenosine $3^{\prime}: 5^{\prime}$ monophosphate (cAMP) levels that induce the synthesis and secretion of transforming growth factor (TGF)- $\beta$ and interleukin (IL) -6 in cultured PDL cells and gingival fibroblasts. ${ }^{8,9}$ Recent data have also indicated that EMD may contain additional mitogenic factors such as TGF- $\beta$ and bone morphogenetic protein (BMP)-like growth factors that stimulate fibroblastic proliferation and contribute to the induction of biomineralization during periodontal regeneration. ${ }^{10-13}$

Observations from human histologic case reports have provided evidence that periodontal regeneration may be accomplished following treatment with GTR or EMD. ${ }^{14-23}$ Data from controlled clinical studies have shown that both therapies may lead to an additional gain of clinical attachment level (CAL) compared to open flap debridement (OFD) alone. ${ }^{24-34}$ On the other hand, no significant differences were found between treatment with EMD or GTR in intrabony defects. ${ }^{26,28,30,35-38}$

Clinical studies on GTR have indicated that the short-term results can be maintained on a long-term basis in the great majority of cases. ${ }^{39-48}$ On the other hand, data presenting the long-term outcome following the treatment of intrabony defects with EMD are still limited. ${ }^{44,45,49-54}$ Moreover, there are virtually no data from comparative, controlled clinical studies evaluating the treatment of intrabony defects with EMD or GTR over a period up to 8 years.

Therefore, the aim of the present controlled clinical trial was to present the clinical results obtained at 8 years following treatment of intrabony defects with EMD or GTR.

\section{MATERIALS AND METHODS}

\section{Study Population}

The study population and the short-term (8-month data) and 4-year results have been described in detail previously. ${ }^{35,44}$ Briefly, a total of 16 patients (six females and 10 males) were included in the study based on a signed informed consent. The study was in accordance with the Helsinki Declaration of 1975 , as revised in 1983 . However, only 10 patients (six females and four males) with a mean age of $46 \pm 7.5$ years (range, 38 to 55 years) completed the 8 -year evaluation. The other six patients were lost during follow-up: three patients refused to participate in the evaluation, and three patients moved away. Therefore, only data from the 10 available patients are presented in the following study.

\section{Patient Selection and Investigated Parameters}

The criteria for the selection of the patients were as follows: 1) presence in the same jaw of one pair of contralateral intrabony defects similar in form and size as observed on radiographs: the intrabony defects presented a depth $\geq 6 \mathrm{~mm}$ when measured with a manual periodontal probe; 2 2) no systemic diseases; 3 ) no use of antibiotics for the last 6 months prior to treatment; 4) no treatment of periodontitis for the last 2 years; and 5) a good level of oral hygiene. As criteria for a good level of oral hygiene a plaque index (PI) score $<1^{55}$ was chosen. Three months prior to surgery, each patient was given thorough oral hygiene instructions and full-mouth supra- and subgingival scaling and root planing under local anesthesia.

One week prior to and after 1 and 8 years following therapy the following clinical parameters were assessed in the whole mouth by the same blinded and previously calibrated investigator: PI and gingival index $(\mathrm{GI}),{ }^{55}$ bleeding on probing (BOP), probing depth (PD), gingival recession (GR), and CAL. The measurements were made at six sites per tooth: mesiobuccal (mb), mid-buccal (m), disto-buccal (db), mesio-lingual (ml), mid-lingual (l), and disto-lingual (dl). In the calculations, only one site representing the same deepest point of the defect was included. The cemento-enamel junction (CEJ) was used as the fixed reference point. In cases where the CEJ was not clearly visible, a restoration margin was used for these measurements. The same periodontal probe was used for all measurements. Prior to the surgery and at 1 and 8 years after treatment, periapical radiographs of the experimental sites were taken with the long-cone parallel technique.

\section{Surgical Procedure}

All operative procedures have been described in detail previously. ${ }^{35}$ Briefly, all treatments were performed by the same operator (AS). Following intracrevicular incisions, full-thickness mucoperiosteal flaps were raised buccally and lingually. The granulation tissue was removed from the defects, and the roots were thoroughly scaled and planed. During surgery, the following measurements were made: the distance from the cemento-enamel junction to the bottom of the defect (CEJ-BD) and distance from the CEJ to the most coronal extension of the alveolar bone crest (CEJ$\mathrm{BC}$ ). The intrabony component (INTRA) of the defects was defined as (CEJ-BD) - (CEJ-BC).

Subsequently, the defects were randomly assigned to treatment with EMD or GTR. When EMD was used, the root surfaces adjacent to the defects were conditioned for 2 minutes with 24\% EDTA gel ( $\mathrm{pH} \mathrm{6.7)})^{\#}$

\footnotetext{
|| PCP 12, Hu-Friedy, Chicago, IL.

II PCP 12, Hu-Friedy.

\# PrefGel, Straumann, Basel, Switzerland; previously, Biora, Malmö, Sweden.
} 
to remove the smear layer. ${ }^{56}$ The defects and the adjacent mucoperiosteal flaps were thoroughly rinsed with sterile saline to remove any residual EDTA. $E M D * *$ was applied on the root surfaces and into the defects, according to the instructions given by the manufacturer, and the flaps were repositioned coronally and closed with vertical or horizontal mattress sutures. Following a period $\leq 2$ weeks, the contralateral intrabony defects were treated with a bioabsorbable membrane. ${ }^{\dagger \dagger}$ At these sites, the root surfaces were scaled and root planed, but no root conditioning with EDTA was performed. The membrane was trimmed and adapted over the defect in such a manner that the entire defect and 2 to $3 \mathrm{~mm}$ of the surrounding alveolar bone were completely covered. The membrane was fixed to the same or to the neighboring teeth with bioabsorbable sutures. ${ }^{\ddagger}$ Flap closure was achieved in the same manner as in the contralateral sites.

\section{Postoperative Management and Long-Term Maintenance}

All patients received antibiotics for 7 days $(3 \times 375 \mathrm{mg}$ amoxicillin $\times 3 \times 275 \mathrm{mg}$ metronidazole per day). ${ }^{57}$ Sutures were removed 14 days after the surgery. The postoperative care consisted of $0.2 \%$ chlorhexidine digluconate solution rinses twice a day for 6 weeks. Only after this period was toothbrushing resumed in the operated areas. Recall appointments were scheduled every second week during the first 2 months following the surgical procedure, and the patients were recalled once per month during the first year postoperatively. After the first year and during the rest of the observation period of 8 years, the patients were recalled every 3 or 6 months. The recall appointments consisted mainly of reinforcement of oral hygiene measures and professional supragingival tooth cleaning.

\section{Statistical Analysis}

The statistical analysis was performed using a software program. $\S \S$ The study was designed for testing superiority. The primary outcome variable was CAL. In these calculations, only the same deepest site per tooth was included. The paired $t$ test was used to compare the data from the baseline to those at 1 and 8 years for each treatment group. Comparisons between treatment groups at baseline and at 1 and 8 years were accomplished with the paired $t$ test. The $\alpha$ error was set at 0.05 . The power of the study, given $1 \mathrm{~mm}$ as a significant difference between groups, was calculated to be 0.60 .

\section{RESULTS}

The observations on the early postoperative healing were described in detail elsewhere. ${ }^{35}$ No adverse re- actions related to the EMD or the bioabsorbable membrane were observed.

At baseline, there were no statistically significant differences in any of the investigated clinical parameters (Tables 1 through 3 ).

The PI, GI, and BOP for both treatment groups at baseline and after 1 and 8 years are summarized in Table 1 . The mean PI did not reveal a statistically significant difference between the two groups at baseline and after 1 and 8 years. Although the PI increased slightly in both treatment groups at 8 years, this difference was not found to be statistically significant compared to the baseline or 1-year results. A statistically significant difference was observed in both treatment groups when comparing the GI and BOP values at 1 and 8 years to the baseline values $(P<0.001)$. However, no statistically significant differences were observed between the 1 - and 8-year results (Table 1).

The baseline defect characteristics are presented in Table 2. No statistically significant difference in the initial depth of the intrabony component was found between the two groups. The distribution of the defects according to their configuration is presented in Table 4.

The PD, GR, and CAL at baseline and 1 and 8 years after treatment are presented in Table 3 . At 1 year, the PD decreased statistically highly significantly in both groups $(P<0.001)$. Between the groups, no statistically significant difference was found. At 8 years, a statistically significant increase in PD was observed in both groups $(P<0.05)$ compared to the 1 -year values. At 8 years, the PD was still statistically highly significantly improved compared to baseline $(P<0.001)$.

At 1 year, the GR increased statistically highly significantly $(P<0.001)$ in both groups compared to baseline, but the difference between the groups was not significant (Table 3 ). No statistically significant difference was found in the GR between baseline and 8 years. The 8 -year GR values improved in both groups compared to the 1 -year results, but the difference reached statistical significance only in the GTR group $(P<0.05)$. No statistically significant differences between the two groups were found at 8 years.

At 1 and at 8 years, the CAL improved statistically highly significantly in both groups compared to baseline $(P<0.001)$ (Table 3$)$. Within the groups and between the two treatments, no statistically significant differences between the 1- and 8-year results were found.

In the EMD group, two defects lost $2 \mathrm{~mm}$ of the CAL gained at 1 year, whereas a CAL loss of $2 \mathrm{~mm}$ was measured at 1 defect of the GTR group.

\footnotetext{
** Emdogain, Straumann; previously, Biora.

$\dagger \dagger$ Resolut, W.L. Gore \& Associates, Inc., Flagstaff, AZ.

\#キ Dexon II, Davis \& Geck, Manati, PR.

$\S \S$ SPSS for Windows 95, SPSS, Chicago, IL.
} 
Table I.

PI, GI, and BOP at Baseline and 1 and 8 Years Following Treatment With EMD or GTR

\begin{tabular}{|c|c|c|c|c|c|c|}
\hline Parameter & Treatment & Baseline & | Year & $P$ Value & 8 Years & $P$ Value \\
\hline \multirow[t]{2}{*}{$\mathrm{Pl}($ mean $\pm \mathrm{SD})$} & EMD & $0.8 \pm 0.5$ & $0.8 \pm 0.4$ & NS & $1.2 \pm 0.6$ & NS \\
\hline & GTR & $0.7 \pm 0.7$ & $0.8 \pm 0.5$ & NS & $1.1 \pm 0.3$ & NS \\
\hline \multirow[t]{2}{*}{$\mathrm{Gl}($ mean $\pm \mathrm{SD})$} & EMD & $1.6 \pm 0.4$ & $0.6 \pm 0.5$ & $<0.001$ & $1.0 \pm 0.7$ & NS \\
\hline & GTR & $1.7 \pm 0.5$ & $0.7 \pm 0.6$ & $<0.00 \mid$ & $1.0 \pm 0.8$ & NS \\
\hline
\end{tabular}

NS $=$ not statistically significant. No significant differences between the EMD and GTR groups were found.

Table 2.

Baseline Defect Characteristics ( $\mathrm{mm}$, mean $\pm \mathrm{SD}$ )

\begin{tabular}{lcccccc}
\hline Treatment & PD & GR & CAL & CEJ-BD & CEJ-BC & INTRA \\
\hline EMD & $8.1 \pm 0.7$ & $1.4 \pm 1.1$ & $9.5 \pm 1.2$ & $10.2 \pm 1.5$ & $6.2 \pm 1.4$ & $4.0 \pm 1.5$ \\
GTR & $8.2 \pm 1.0$ & $1.5 \pm 1.7$ & $9.7 \pm 1.3$ & $10.6 \pm 1.6$ & $6.5 \pm 1.3$ & $4.1 \pm 1.4$ \\
\hline
\end{tabular}

Table 3.

\section{Clinical Parameters (mean \pm SD) at Baseline and 1 and 8 Years Following Treatment With EMD or GTR}

\begin{tabular}{|c|c|c|c|c|c|c|}
\hline Parameter & Treatment & Baseline & I Year & $P$ Value & 8 Years & $P$ Value \\
\hline \multirow[t]{2}{*}{ PD } & EMD & $8.1 \pm 0.7$ & $4.0 \pm 0.8$ & $<0.001$ & $4.7 \pm 1.2$ & $<0.05$ \\
\hline & GTR & $8.2 \pm 1.0$ & $3.6 \pm 0.5$ & $<0.001$ & $4.5 \pm 0.8$ & $<0.05$ \\
\hline \multirow[t]{2}{*}{ GR } & EMD & $1.4 \pm 1.1$ & $2.3 \pm 0.8$ & $<0.001$ & $2.0 \pm 0.6$ & NS \\
\hline & GTR & $1.5 \pm 1.7$ & $3.1 \pm 1.0$ & $<0.001$ & $2.3 \pm 1.2$ & $<0.05$ \\
\hline
\end{tabular}

NS = not statistically significant. No significant differences between the EMD and GTR groups were found.

\section{DISCUSSION}

The results of the present study have shown that the treatment of intrabony defects with EMD or GTR results in significant reductions in PD and gains of CAL that can be maintained over a period of 8 years. No statistically significant differences between the two treatment modalities in any of the investigated clinical parameters were found at 1 and 8 years after therapy. In both groups, a slight but not statistically significant loss of mean CAL was measured between the 1 - and 8-year evaluation periods. On one hand, this slight loss of mean CAL may probably be attributed to the $2 \mathrm{~mm}$ of CAL loss that occurred in both groups at some of the defects (i.e., at two defects treated with EMD and at one defect treated with GTR). On the other hand, in both groups, the mean PD increased statistically significantly from 1 to 8 years, whereas the mean GR showed a tendency for improvement in the same time. In both treatment groups, the statistically significant increase in PD between 1 and 8 years can be explained by the higher values of PI, which were slightly higher than the baseline values. Although at 8 years the increase in mean PI, GI, and BOP did not reach statistical significance compared to the baseline and 1 -year values, it cannot be excluded that the plaque accumulation might have led to inflammation and loss of CAL. Results from controlled clinical studies have shown that the stability of gained clinical attachment following conventional and regenerative periodontal therapy is dependent upon stringent oral hygiene 
Table 4.

\section{Distribution and Configuration of Treated Defects}

\begin{tabular}{ccc}
\hline & EMD & GTR \\
\hline I-wall & 1 & 1 \\
2-wall & 8 & 7 \\
3-wall & 1 & 2 \\
\hline
\end{tabular}

and compliance with a supportive periodontal care program. ${ }^{41,46,58}$ Furthermore, it has to be noted that only 10 out of the original 16 patients were included in the present follow-up study. Thus, it is unknown to what extent the lack of six patients might have influenced the 8-year results. Another important factor that was demonstrated to strongly influence the outcome of regenerative periodontal treatment is smoking. ${ }^{58}$ However, due to the fact that none of the 10 patients was a smoker, no conclusion can be drawn regarding this issue.

Taken together, these observations may also suggest that a remodeling of the soft tissues may take place without major changes in CAL on a long-term basis. Similar observations were made in other studies evaluating the long-term outcome of conventional and regenerative periodontal therapy. ${ }^{45,52,59,60}$ It is also important to realize that the study does not have the statistical power to rule out the possibility of a difference between the two groups. Further studies of much higher power need to be performed to support equivalence and to evaluate the possible factors affecting periodontal tissue remodeling on a long-term basis. ${ }^{61}$

The finding that the treatment of intrabony defects with EMD may result in statistically significantly improvements in PD and CAL compared to baseline on a short-term basis is in agreement with previously reported data. ${ }^{25-38}$ To the best of our knowledge, there are no other data from prospective, controlled clinical studies reporting the outcome of EMD treatment up to an 8-year period. In the first controlled clinical trial comparing the treatment of intrabony defects with EMD to that with flap surgery, Heijl et al. ${ }^{25}$ reported a mean CAL gain of $2.1 \mathrm{~mm}$ after treatment with EMD and of $1.5 \mathrm{~mm}$ after flap surgery alone (control) at 8 months. At 36 months, the mean CAL gain was $2.2 \mathrm{~mm}$ for EMD-treated sites and $1.7 \mathrm{~mm}$ for controls. At 1 and 8 years, the mean CAL gains obtained in the present study were higher than that reported by Heijl et al. ${ }^{25}$ Factors contributing to this difference might be the defect type and the initial depth of the defect. In the present study, the majority of defects were 2 -wall defects, whereas the defects in the study by Heijl et al. ${ }^{25}$ displayed a predominantly 1 -wall configuration. Results from controlled clinical studies have provided evidence that 2 - and 3-wall defects have a greater healing potential than 1 -wall defects after conventional and regenerative periodontal surgery. ${ }^{58,62}$ Furthermore, in the present study, the mean initial defect depth was somewhat higher than in the previously mentioned study. ${ }^{25}$ Clinical studies have demonstrated that the CAL gain after any type of periodontal treatment is strongly dependent upon the initial PD (i.e., the deeper the initial defect, the greater the PD reduction and CAL gain). ${ }^{33,58-60}$ The present results are in agreement with recent data from case reports and controlled clinical studies evaluating the long-term treatment of intrabony defects with EMD. ${ }^{44,45,49-54}$ In a 4-year follow-up study, a total of 46 intrabony defects in 33 patients were consecutively treated with EMD. ${ }^{52}$ At 4 years, the results indicated a stability of the 1 -year results. Moreover, the reentry surgery performed after 4 years in one case demonstrated an almost complete fill of the intrabony component. These findings are in line with very recent observations made in three cases reentered after 7 years following treatment with EMD. ${ }^{54}$ Furthermore, results from a prospective, controlled clinical study evaluating the treatment of intrabony defects with EMD, GTR, EMD plus GTR, and OFD have shown that the short-term clinical results following these treatments can be maintained over a period of 5 years. ${ }^{45}$ Thus, the present 8 -year results are consistent with those reported by others after 3, 4, 5, and 7 years and indicate that the obtained clinical results with $\mathrm{EMD}$ may be maintained even up to 8 years when an adequate plaque control program is maintained. $44,45,49-54$

The present results obtained with GTR are also in agreement with those from other clinical studies that indicate that the clinical improvements obtained following treatment with GTR can be maintained over a longer time period if an optimal patient and defect selection are accomplished. ${ }^{39-48}$ A recent retrospective study evaluated a total of 175 patients with one deep intrabony defect treated with GTR. The results suggested that the clinical improvements obtained following the treatment of intrabony defects with GTR can be maintained over a period of up to 16 years; thus, this treatment approach represents an important modality for maintaining severely compromised teeth. ${ }^{46}$

However, it should be also pointed out that the exposure of the membrane material, which is a common complication in GTR therapy, is absent following treatment with EMD. ${ }^{38,63}$ This fact, coupled with the finding that both treatments have been shown to result in comparable histologic and clinical results, may suggest that treatment with EMD might be preferred 
to GTR from a clinical point of view, especially in cases where the defects are self-containing and an adequate membrane fixation and soft tissue coverage are technically demanding. ${ }^{19,38,64}$

\section{CONCLUSION}

Within their limits, the present results indicate the following: 1) the clinical improvements obtained following treatment with EMD or GTR can be maintained over a period of 8 years, and 2) further studies of much higher power need to be performed to support equivalence.

\section{REFERENCES}

1. Caton JG, Greenstein GG. Factors related to periodontal regeneration. Periodontol 2000 1993;1:9-15.

2. Bowers GG, Chadroff B, Carnevale R, et al. Histologic evaluation of new human attachment apparatus formation in humans. Part I. J Periodontol 1989;60:664-674.

3. Brunsvold MA, Mellonig JT. Bone grafts and periodontal regeneration. Periodontol 2000 1993;1: 80-91.

4. Lowenguth RA, Blieden TM. Periodontal regeneration: Root surface demineralization. Periodontol 2000 1993; 1:54-68.

5. Karring T, Nyman S, Gottlow J, Laurell L. Development of the biological concept of guided tissue regeneration - Animal and human studies. Periodontol 2000 1993;1:26-35.

6. Lynch SE, Williams RC, Polson AM. A combination of platelet-derived and insulin-like growth factors enhances periodontal regeneration. J Clin Periodontol 1989;16:545-548.

7. Hammarström L. Enamel matrix, cementum development and regeneration. J Clin Periodontol 1997;24: 658-668.

8. Lyngstadaas SP, Lundberg E, Ekdahl H, Andersson C, Gestrelius S. Autocrine growth factors in human periodontal ligament cells cultured on enamel matrix derivative. J Clin Periodontol 2001;28:181-188.

9. Okubo K, Kobayashi M, Takiguchi T, et al. Participation of endogenous IGF-I and TGF-beta 1 with enamel matrix derivative-stimulated cell growth in human periodontal ligament cells. J Periodontal Res 2003; 38:1-9.

10. Kawase T, Okuda K, Momose M, Kato Y, Yoshie H, Burns DM. Enamel matrix derivative (EMDOGAIN) rapidly stimulates phosphorylation of the MAP kinase family and nuclear accumulation of smad2 in both oral epithelial and fibroblastic human cells. J Periodontal Res 2001;36:367-376.

11. Kawase T, Okuda K, Yoshie H, Burns DM. Anti-TGFbeta antibody blocks enamel matrix derivativeinduced upregulation of $\mathrm{p} 21 \mathrm{WAF} 1 / \mathrm{cip} 1$ and prevents its inhibition of human oral epithelial cell proliferation. $J$ Periodontal Res 2002;37:255-262.

12. Suzuki S, Nagano T, Yamakoshi Y, et al. Enamel matrix derivative gel stimulates signal transduction of BMP and TGF- $\beta$. J Dent Res 2005;84:510-514.

13. Takayama T, Suzuki N, Narukawa M, Tokunaga T, Otsuka K, Ito K. Enamel matrix derivative stimulates core binding factor alpha1/Runt-related transcription factor-2 expression via activation of Smad in C2C12 cells. J Periodontol 2005;76:244-249.
14. Nyman S, Lindhe J, Karring T, Rylander H. New attachment following surgical treatment of human periodontal disease. J Clin Periodontol 1982;9: 290-296.

15. Gottlow J, Nyman S, Lindhe J, Karring T, Wennström $\mathrm{J}$. New attachment formation in the human periodontium by guided tissue regeneration. Case reports. $J$ Clin Periodontol 1986;13:604-616.

16. Sculean A, Donos N, Chiantella GC, Windisch P, Reich E, Brecx M. Treatment of intrabony defects with bioabsorbable membranes. A clinical and histologic study. Int J Periodontics Restorative Dent 1999;19: 501-509.

17. Mellonig JT. Enamel matrix derivative for periodontal reconstructive surgery: Technique and clinical and histologic case report. Int $J$ Periodontics Restorative Dent 1999;19:8-19.

18. Heijl L. Periodontal regeneration with enamel matrix derivative in one human experimental defect. A case report. J Clin Periodontol 1997;24:693-696.

19. Sculean A, Donos N, Windisch P, et al. Healing of human intrabony defects following treatment with enamel matrix proteins or guided tissue regeneration. J Periodontal Res 1999;34:310-322.

20. Yukna RA, Mellonig J. Histologic evaluation of periodontal healing in humans following regenerative therapy with enamel matrix derivative. A 10-case series. J Periodontol 2000;71:752-759.

21. Sculean A, Chiantella GC, Windisch P, Donos N. Clinical and histologic evaluation of human intrabony defects treated with an enamel matrix protein derivative (Emdogain). Int $J$ Periodontics Restorative Dent 2000;20:374-381.

22. Bosshardt DD, Sculean A, Windisch P, Pietursson BE, Lang NP. Effects of enamel matrix proteins on tissue formation along the roots of human teeth. J Periodontal Res 2005;40:158-167.

23. Mazjoub Z, Bobbo M, Atiyeh F, Cordioli G. Two patterns of histologic healing in an intrabony defect following treatment with an enamel matrix derivative: A human case report. Int $J$ Periodontics Restorative Dent 2005;25:283-294.

24. Cortellini P, Pini Prato G, Tonetti MS. Periodontal regeneration of human intrabony defects with bioresorbable membranes. A controlled clinical trial. $J$ Periodontol 1996;67:217-223.

25. Heijl L, Heden G, Svardström G, Östgren A. Enamel matrix derivative (Emdogain) in the treatment of intrabony periodontal defects. J Clin Periodontol 1997; 24:705-714.

26. Pontoriero R, Wennström J, Lindhe J. The use of barrier membranes and enamel matrix proteins in the treatment of angular bone defects. A prospective controlled clinical study. J Clin Periodontol 1999; 26:833-840.

27. Okuda K, Momose M, Miyazaki A, et al. Enamel matrix derivative in the treatment of human intrabony osseous defects. J Periodontol 2000;71:1821-1828.

28. Silvestri M, Ricci G, Rasperini G, Sartori S, Cattaneo V. Comparison of treatments of intrabony defects with enamel matrix derivative, guided tissue regeneration with a nonresorbable membrane and Widman modified flap. A pilot study. J Clin Periodontol 2000;27: 603-610.

29. Froum SJ, Weinberg MA, Rosenberg E, Tarnow D. A comparative study utilizing open flap debridement with and without enamel matrix derivative in 
the treatment of periodontal intrabony defects: A 12-month re-entry study. J Periodontol 2001;72: 25-34.

30. Sculean A, Windisch P, Chiantella GC, Donos N, Brecx $M$, Reich E. Treatment of intrabony defects with enamel matrix proteins and guided tissue regeneration. A prospective controlled clinical study. J Clin Periodontol 2001;28:397-403.

31. Tonetti MS, Lang NP, Cortellini P, et al. Enamel matrix proteins in the regenerative therapy of deep intrabony defects. A multicenter randomized controlled clinical trial. J Clin Periodontol 2002;29:317-325.

32. Wachtel H, Schenk G, Bohm S, Weng D, Zuhr O, Hurzeler MB. Microsurgical access flap and enamel matrix derivative for the treatment of periodontal intrabony defects: A controlled clinical study. J Clin Periodontol 2003;30:496-504.

33. Francetti L, Trombelli L, Lombardo G, et al. Evaluation of efficacy of enamel matrix derivative in the treatment of intrabony defects: A 24-month multicenter study. Int J Periodontics Restorative Dent 2005;25: 461-473.

34. Rösing CK, Aass AM, Mavropoulos A, Gjermo P. Clinical and radiographic effects of enamel matrix derivative in the treatment of intrabony periodontal defects: A 12-month longitudinal placebo-controlled clinical trial in adult periodontitis patients. J Periodontol 2005;76:129-133.

35. Sculean A, Donos N, Blaes A, Lauermann M, Reich E, Brecx M. Comparison of enamel matrix proteins and bioabsorbable membranes in the treatment of intrabony periodontal defects. A split-mouth study. J Periodontol 1999;70:255-262.

36. Zucchelli G, Bernardi F, Montebugnoli L, De Sanctis M. Enamel matrix proteins and guided tissue regeneration with titanium-reinforced expanded polytetrafluoroethylene membranes in the treatment of intrabony defects: A comparative controlled clinical trial. J Periodontol 2002;73:3-12.

37. Silvestri M, Sartori S, Rasperini G, Ricci G, Rota C, Cattaneo V. Comparison of intrabony defects treated with enamel matrix derivative versus guided tissue regeneration with a nonresorbable membrane. J Clin Periodontol 2003;30:386-393.

38. Sanz M, Tonetti MS, Zabalegui I, et al. Treatment of intrabony defects with enamel matrix proteins or barrier membranes: Results from a multicenter practice-based clinical trial. J Periodontol 2004;75:726-733.

39. Gottlow J, Nyman S, Karring T. Maintenance of new attachment gained through guided tissue regeneration. J Clin Periodontol 1992;19:315-317.

40. Weigel C, Brägger U, Hämmerle CHF, Mombelli A, Lang NP. Maintenance of new attachment 1 and 4 years following guided tissue regeneration (GTR). J Clin Periodontol 1995;22:661-669.

41. Cortellini P, Pini Prato GP, Tonetti MS. Long-term stability of clinical attachment following guided tissue regeneration and conventional therapy. J Clin Periodontol 1996;23:106-111.

42. Cortellini P, Stalpers G, Pini Prato G, Tonetti M. Longterm clinical outcomes of abutments treated with guided tissue regeneration. J Prosthet Dent 1999;81: 305-311.

43. De Sanctis $M$, Zucchelli G. Interleukin-1 gene polymorphism and long-term stability following guided tissue regeneration therapy. J Periodontol 2000;71: 606-613.
44. Sculean A, Donos N, Miliauskaite A, Arweiler N, Brecx $M$. Treatment of intrabony defects with enamel matrix proteins or bioresorbable membranes. A four year follow up split-mouth study. J Periodontol 2001;72: 1695-1701.

45. Sculean A, Donos N, Schwarz F, Becker J, Brecx M, Arweiler NB. Five year results following treatment of intrabony defects with enamel matrix proteins and guided tissue regeneration. J Clin Periodontol 2004; 31:545-549.

46. Cortellini P, Tonetti MS. Long-term tooth survival following regenerative treatment of intrabony defects. J Periodontol 2004;75:672-678.

47. Eickholz P, Krigar DM, Pretzl B, Steinbrenner H, Dörfer C, Kim TS. Guided tissue regeneration with bioabsorbable barriers. II. Long-term results in infrabony defects. $J$ Periodontol 2004;75:957-965.

48. Stavropoulos A, Karring T. Long-term stability of periodontal conditions achieved following guided tissue regeneration with bioresorbable membranes: Case series results after 6-7 years. J Clin Periodontol 2004; 31:939-944.

49. Zetterström O, Andersson C, Eriksson L, et al. Clinical safety of enamel matrix derivative (Emdogain) in the treatment of periodontal defects. J Clin Periodontol 1997;24:697-704.

50. Parodi R, Santarelli GAE, Gasparetto BEE. Treatment of intrabony defects with Emdogain: Results at 36 months. Int J Periodontics Restorative Dent 2004;24: 57-63.

51. Glise JM, Blanc A, Monnet-Corti VM, Borghetti A. Results at 3 years of treatment of intrabony defects with enamel matrix proteins (in French). J Parodontol Implantol Orale 2005;23:189-196.

52. Sculean A, Chiantella GC, Miliauskaite A, Brecx M, Arweiler NB. Four-year results following treatment with an enamel matrix protein derivative: A report of 46 cases. Int J Periodontics Restorative Dent 2003; 23:345-351.

53. Heden G, Wennström JL. Five-year follow-up of regenerative periodontal therapy with enamel matrix derivative at sites with angular bone defects. J Periodontol 2006;77:295-301.

54. Rasperini G, Silvestri M, Ricci G. Long-term clinical observation of treatment of infrabony defects with enamel matrix derivative (Emdogain): Surgical reentry. Int $J$ Periodontics Restorative Dent 2005;25:121-127.

55. Löe H. The Gingival Index, the Plaque Index and the Retention Index system. J Periodontol 1967;38:610-616.

56. Blomlöf JPS, Blomlöf LB, Lindskog SF. Smear removal and collagen exposure after non-surgical root planing followed by etching with EDTA gel preparation. J Periodontol 1996;67:841-845.

57. van Winkelhoff AJ, Rodenburg JP, Goené RJ, Abbas F, Winkel EG, de Graaff J. Metronidazole plus amoxycillin in the treatment of Actinobacillus actinomycetemcomitans associated periodontitis. J Clin Periodontol 1989;16:128-131.

58. Tonetti MS, Pini Prato G, Cortellini P. Factors affecting the healing response of intrabony defects following guided tissue regeneration and access flap surgery. J Clin Periodontol 1996;23:548-556.

59. Ramfjord S, Caffesse R, Morrison E, et al. 4 modalities of periodontal treatment compared over 5 years. $J$ Clin Periodontol 1987;14:445-452.

60. Kaldahl WB, Kalkwarf KL, Patil KD, Molvar MP, Dyer JK. Long-term evaluation of periodontal therapy: I. 
Response to 4 therapeutic modalities. J Periodontol 1996;67:93-102.

61. Gunsolley JC, Elswick RK, Davenport JM. Equivalence and superiority testing in regeneration clinical trials. J Periodontol 1998;69:521-527.

62. Polson AM, Heijl LC. Osseous repair in infrabony periodontal defects. J Clin Periodontol 1978;5: 13-23.

63. Nowzari H, Matian F, Slots J. Periodontal pathogens on polytetrafluoroethylene membrane for guided tissue regeneration inhibit healing. $J$ Clin Periodontol 1995;22:469-474.
64. Cortellini P, Tonetti MS. Clinical performance of a regenerative strategy for intrabony defects: Scientific evidence and clinical experience. J Periodontol 2005; 76:341-350.

Correspondence: Dr. Anton Sculean, Department of Periodontology, Radboud University Medical Center, P.O. Box 9101, Internal Postal Code 117, 6500 Nijmegen, Philips van Leydenlaan 25, The Netherlands. Fax: 31-24-361-4657; e-mail: a.sculean@dent.umcn.nl.

Accepted for publication June 20, 2006. 